\title{
RISK FACTORS FOR DISABILITY AMONG U.S. ADULTS WITH ARTHRITIS*
}

\author{
Lois M. Verbrugge, ${ }^{\dagger} \nmid$ Donna M. Gates ${ }^{2}$ and Robert W. IKE ${ }^{3}$ \\ ${ }^{1}$ Institute of Gerontology, The University of Michigan, Ann Arbor, ${ }^{2}$ Department of Psychology, \\ State University of New York, Binghamton, NY 13901 and ${ }^{3}$ Division of Rheumatology, University \\ of Michigan Medical Center, Ann Arbor, MI 48109, U.S.A. \\ (Received in revised form 8 August 1990)
}

\begin{abstract}
This article studies risk factors for physical and social disability among U.S. adults ages $55+$ who have arthritis, compared to non-arthritis persons of those ages. The dependent variables refer to difficulties in walking, physical functioning (motions and strength), personal care, and household care. The data set is the Supplement on Aging (SOA) $(n=16,148)$ that accompanied the 1984 National Health Interview Survey. The SOA data are cross-sectional; relationships of risk factors to disability suggest causation but do not directly demonstrate it. Logistic regressions show that risk factors are similar for arthritis and non-arthritis people, with one important exception. (1) The similarities are: For both groups, odds of disability rise with age, diminish with education, and are higher for non-whites and non-married persons. Disability rises with number of chronic diseases and impairments, and it is elevated for underweight persons (Body Mass Index (BMI) <20; further analysis indicates this reflects incomplete control of their severe illness status). Long duration of arthritis and recent medical care for it are associated with disability. (2) The exception is: Severe overweight (BMI $\geqslant 30)$ is a disability risk factor for arthritis people, but not for non-arthritis people. Previous research has shown that obesity/overweight is a risk factor for etiology of osteoarthritis; our analysis now shows its continued importance for disability when the disease is present.
\end{abstract}

Arthritis Disability Overweight (obesity) Comorbidity

\section{INTRODUCTION}

Arthritis is the leading chronic condition in mid and late life, and the leading cause of symptoms and limitations at those ages [1,2], but it rarely causes death. (The most common form, osteoarthritis, is degenerative and nonfatal. One form, rheumatoid arthritis, does shorten life by several years $[3,4]$.) High prevalence combined with

*Early versions of this article were presented at the 1988 meetings of the Population Association of America and the American Rheumatism Association (now American College of Rheumatology).

†All correspondence should be addressed to: Lois $M$. Verbrugge, Institute of Gerontology, 300 North Ingalls, The University of Michigan, Ann Arbor, MI 481092007, U.S.A. [Tel. 313-936-2103]. negligible fatality results in a heavy toll on physical and social functioning for older adults, both individually and collectively. What factors elevate disability among people with arthritis? Are any of the risk factors distinctive; i.e. prompting disability for arthritis people but not for non-arthritis people?

This article studies risk factors for disability among U.S. adults with arthritis, compared to adults without arthritis, using the 1984 Supplement on Aging conducted by the National Center for Health Statistics. Rates of arthritis for the U.S. population ages $55+$ are estimated from the survey. Levels of disability in physical and social functions are described for arthritis and non-arthritis persons. Sociodemographic 
and medical characteristics of respondents that are potential risk factors for disability are stated, with hypotheses. Logistic regressions with cross-sectional net effects of predictors on disability are estimated separately for arthritis and non-arthritis groups. Severe overweight proves to be a distinctive risk factor for disability among arthritis people.

Other research has shown that overweight is strongly implicated in disease etiology, especially for osteoarthritis [5-12]. Our results show that overweight is also implicated in disability, once arthritis is present.

\section{MATERIALS AND METHODS}

\section{Data source}

The Supplement on Aging (SOA) accompanied the 1984 National Health Interview Survey conducted by the National Center for Health Statistics (NCHS). The SOA is based on a probability sample of the U.S. civilian noninstitutional population ages 55+ [13]. Altogether 16,148 persons were interviewed.

The SOA has a complex probability sample; we adjust here for disproportionate sampling and response by using weights provided by NCHS. The arthritis and disability rates are thus estimates for the national population. Complex variances that adjust for cluster sampling are not used. Computed variances are thus underestimates, and we view results at the 0.05 level $(0.01<p \leqslant 0.05)$ as suggestive. Results significant at the 0.01 level $(p \leqslant 0.01)$ are considered equivalent to 0.05 . (This simple rule is based on statistical research on design effects [14-17]. Adjusting for complex variances affects total estimates, such as means, far more than regression coefficients; so our use of the rule is a conservative stance.)

\section{Arthritis}

In rheumatology, the term "arthritis" encompasses over 100 specific diseases whose primary, but not always sole manifestations involve the joints [18]. The most common arthropathy is osteoarthritis (OA) (also called degenerative joint disease, or osteoarthrosis). Epidemiological research has identified some factors associated with OA: occupations involving repetitive impact loading on joints, prior injury at or near joints, and obesity [reviews in 19-25]. Rheumatoid arthritis (RA) ranks second but is far less prevalent than osteoarthritis. The other arthropathies (e.g. ankylosing spondylitis, crystal- induced arthritis, infective or allergic arthritis) are uncommon. Rheumatoid arthritis and ankylosing spondylitis are both thought to be spurred by immune system disorders.

In the SOA, arthritis status is based on selfreported chronic conditions that are extensively probed by interviewers for diagnosis name, symptoms, duration, etc. and then medically coded by a special team of NCHS coders. They assign the most specific International Classifcation of Diseases (ICD) code possible to each condition. (None of the probed details are separately coded.) An ICD code for arthritis occurs in two basic situations: (1) when the respondent states that a physician or physician's assistant diagnosed the condition as "arthritis" (either that name or a more specific one such as "osteoarthritis") or (2) when a non-diagnosed respondent uses that term and all additional details recorded about the condition corroborate it. The span of ICD-9-CM codes for arthritis used by NCHS is: $711 . b, 0,9 ; 712 . b, 8,9$; $714-716 ; 720.0 ; 721$. (The letter " $b$ " denotes blank. Three-digit entries are inclusive of all fourth digits $b, 0-9$.) The specific titles are listed in Appendix 1. Excluded from arthritis are such conditions as vertebrogenic pain syndrome, cervical/spinal stenosis, regional pain/stiffness of unknown disease origin, and gout (a metabolic disorder with pronounced joint symptoms).

Fourteen percent $(14 \%)$ of the arthritis conditions reported in the SOA had sufficient information for specific disease codes: $5 \%$ are osteoarthritis (ICD 715), 3\% are rheumatoid arthritis (714.0), 6\% are axial arthropathy (721) (or spondylosis; this is non-inflammatory osteoarthritis of back), and less than $1 \%$ are other forms. The data set does not allow us to check the diagnostic accuracy of these specific titles.

The large majority of arthritis conditions $(86 \%)$ are coded as non-specific arthritis (ICD 716.9). Medical coders determined that some form of arthritis was present but could not arrive at a more precise title. Most of the conditions are almost certainly osteoarthritis, though there is no way to prove that.

The number of persons with arthritis in the data set is 7395 (unweighted; 7057 weighted). Our analyses focus on this arthritis group as a whole. This approach is in keeping with the scope of arthritis in national statistics from the National Health Interview Survey. For readers specializing in the rheumatic diseases, we also estimate models for three key subgroups: osteoarthritis (OA), rheumatoid arthritis (RA), and 
axial arthritis (AA). OA contains non-spinal (715) and unstated (716.9) locations of arthritis. RA is specified rheumatoid arthritis (714.0), plus a few cases of unspecified inflammatory polyarthropathy (714.9). AA is cases with (osteo)arthritis in the spine or neck (721). The numbers of persons in the three subgroups are 6950,249 , and 437 (unweighted), respectively, and 6575,255 , and 385 (weighted). Given the small sample sizes for RA and AA, we view any distinctive results for them as only suggestive.

The non-arthritis comparison group is all persons without arthritis. Their number is $\mathbf{8 7 5 3}$ (unweighted; 9190 weighted).

\section{Disability}

Arthritis causes pain, limited motion, and deformity in the affected sites. These make it difficult for people to accomplish daily tasks easily, rapidly, or at all.

We distinguish two kinds of disability: physical disability refers to basic musculoskeletal functions such as bending, lifting, walking. Social disability refers to "whole" social tasks such as eating, dressing, going shopping. Arthritis initially causes physical dysfunctions, and these in turn can induce social dysfunctions. Medical, psychosocial, and environmental factors can increase or decrease the likelihood of disability; the former are risk factors and the latter are buffers. This conceptual scheme is described more fully elsewhere [26].

Disability instruments developed in gerontology research and used in community surveys such as the SOA emphasize social disability in personal care and household tasks [27-31]. Personal care tasks are referred to as "(basic) activities of daily living" (ADL), and household tasks as "instrumental activities of daily living" (IADL). Other valued but more discretionary activities of daily life such as hobbies and civic participation are queried less often.

Disability analyses sometimes focus on degree of difficulty in performing a task, sometimes on dependency (whether respondent needs help from another person to do task). Choosing "difficulty" reflects interest in measuring disease consequences on a person's capabilities, whereas "dependency" reflects interest in use of and needs for longterm care. In this article, we use difficulty items; our goal is to locate sociodemographic and medical factors that prompt dysfunction among persons with arthritis.

We study five dichotomously-coded dependent variables. For physical disability, 1 item refers to gross mobility (any difficulty walking) and 2 items to local motions and strength (any functional limitation; $5+$ functional limitations). Functional limitations are common, so we study both a low threshold of disability (any) and a high threshold $(5+)$. For social disability, there is 1 item for personal care (any ADL difficulty) and 1 for household care (any IADL difficulty). Social disabilities are not common (data shown soon), so only one threshold (any) is studied.

The walking item is based on a single question. The other 4 items are based on multiple questions about specific activities. (For the latter, our analyses identify risk factors for difficulty in broad activity arenas, rather than very specific activities. We consider this a suitable stance for the SOA since it lacks specificity about the location and clinical status of arthritis conditions. If such information were available, one would seek to identify specific functional outcomes of upper and lower extremity disease, of symptomatic and asymptomatic disease, etc. In its absence, it is sensible to study more global outcomes, deferring the specific analyses for a richer arthritis-focused data set.) Appendix 2 shows question wordings for all 5 items.

\section{Predictors}

The predictors are divided into three groups: (1) Sociodemographic characteristics are fixed features of the individual that can influence disease severity and adaptation. We study age, gender, race, marital status, and education. (2) Comorbidity comprises other health problems present which could, by themselves or interacting with arthritis, cause disability. We use a count of other chronic diseases (besides arthritis), a count of structural/sensory impairments, and an overweight indicator (Body Mass Index, or BMI). A variety of overweight measures were assessed for this analysis, including BMI (also known as Quetelet index) (weight/height ${ }^{2}$, weight (kg), height (m)), Metropolitan Relative Weight (using the 1959 Metropolitan Life tables as denominator; sex-specific, medium frame), and Internal Relative Weight (using SOA regressions of weight $=f$ [height] as denominator; sexspecific). These proved very similar in their associations with disability, so we opted for the simplest and widely-known BMI. Useful discussions of overweight indicators are in Refs [32-36]. (3) Target Morbidity covers aspects of the person's arthritis condition that can 
augment disability. The sole items available in the SOA are duration (time since condition was first noticed by respondent or physician), treatment status (recency of care for arthritis), and injury origin (attributed by respondent). Note that target morbidity items exist only for the arthritis group; they are inapplicable for the non-arthritis group. Ideally, we would like to include items about arthritis site(s), pain, botheration, and medically-defined severity. But the data set was not constructed to answer such disease-specific questions. Our analysis uses maximally the information that is available for target (arthritis) morbidity.

\section{Hypotheses}

The predictors are all potential risk factors for disability. We hypothesize these net effects for arthritis people: (1) Probabilities of disability rise with age, diminish with education, and are higher for females, non-whites, and nonmarried persons. These hypotheses parallel sociodemographic differentials commonly found in health research (for gender [37-39]; for marital status, [40-42]; for education [43-47]). The precise risks embedded in the social characteristics and gender are not yet known. (2) Disability is more likely as numbers of (other) chronic diseases and impairments rise, and for overweight people. (There is a large research literature on effects of overweight on mortality, chronic disease, and psychosocial outcomes; reviews and empirical examples are in [48-53].) (3) Long duration of arthritis and recent medical care for arthritis indicate greater severity; these are the best measures of severity available in the SOA. Disability is expected to rise with duration and to decline with time since medical care. No hypothesis is stated for injury origin; we explore if it elevates disability or not.

\section{RESULTS}

\section{Arthritis prevalence}

Based on the SOA, prevalence rates of arthritis increase with age up to $85+$, and are higher for women than men at all ages (Table 1). Rates for OA, RA, and AA from the SOA are also shown. The stasis or small decline in arthritis rates at very elderly ages is counter to clinical evidence and medical knowledge about the condition, yet other scientific studies have found the same phenomenon [54-56].
Table 1. Arthritis prevalence rates for age-sex groups. U.S., 1984 (rates expressed as percents)

\begin{tabular}{|c|c|c|c|}
\hline Age & Male & Female & $\mathbf{F} / \mathbf{M}$ \\
\hline $\begin{array}{l}\text { Arthritis (ICD 7ll.b,0,9; } \\
55-64 \\
65-74 \\
75-84 \\
85+ \\
\quad \text { Total }(55+)\end{array}$ & $\begin{array}{l}712 . b, 8 \\
29.5 \\
40.1 \\
39.6 \\
36.7 \\
34.8\end{array}$ & $\begin{array}{c}714-716 \\
44.3 \\
53.6 \\
58.2 \\
55.0 \\
50.6\end{array}$ & $\begin{array}{c}720.0 ; 721)^{*} \\
1.50 \\
1.34 \\
1.47 \\
1.50 \\
1.45\end{array}$ \\
\hline $\begin{array}{l}\text { Osteoarthritis (ICD } 715 \text {; } \\
55-64 \\
65-74 \\
75-84 \\
85+ \\
\quad \text { Total }\end{array}$ & $\begin{array}{l}7(6.9) \\
27.4 \\
38.0 \\
37.7 \\
35.4 \\
32.7\end{array}$ & $\begin{array}{l}40.7 \\
49.8 \\
55.7 \\
53.1 \\
47.1\end{array}$ & $\begin{array}{l}1.49 \\
1.31 \\
1.65 \\
1.50 \\
1.44\end{array}$ \\
\hline $\begin{array}{l}\text { Rheumatoid arthritis (ICL } \\
55-64 \\
65-74 \\
75-84 \\
85+ \\
\quad \text { Total }\end{array}$ & $\begin{array}{l}D 714.0 \\
1.0 \\
0.8 \\
1.0 \\
0.6 \\
0.9\end{array}$ & $\begin{array}{l}2.1 \\
2.3 \\
1.3 \\
1.6 \\
2.0\end{array}$ & $\begin{array}{l}2.2 \\
3.0 \\
1.3 \\
2.7 \\
2.2\end{array}$ \\
\hline $\begin{array}{l}\text { Axial arthritis } \\
\text { (spondylosis and allied dis } \\
55-64 \\
65-74 \\
75-84 \\
85+ \\
\quad \text { Total }\end{array}$ & $\begin{array}{c}\text { sarders, } \\
1.9 \\
2.7 \\
1.8 \\
1.9 \\
2.1\end{array}$ & $\begin{array}{l}D 721) \\
2.4 \\
3.3 \\
2.8 \\
1.7 \\
2.7\end{array}$ & $\begin{array}{l}1.3 \\
1.2 \\
1.6 \\
0.9 \\
1.3\end{array}$ \\
\hline
\end{tabular}

Source: 1984 Supplement on Aging.

$M$, male; F, female.

*International Classification of Disenses codes (ICD-9 as adapted in National Center for Health Statistics, Medical Coding Manual) [80, 81]. " $b$ " denotes blank. Three-digit entries are inclusive of all fourth digits (b.0-9); e.g. 721 includes $721.6,0-9$.

†Stated as osteoarthritis/degenerative joint disease (715) or unspecified "arthritis" (716.9).

The reasons are not yet known; it may reflect institutionalization of elderly persons with severe cases of arthritis (thus siphoned away from the community-dwelling population represented in the SOA) and, to a lesser extent, early mortality of people with rheumatoid arthritis.

The rates in Table 1 are very similar to those based on the annual National Health Interview Survey (published in Vital and Health Statistics, Series 10). Population-based rates for specific arthropathies based on medical criteria, rather than health interviews, are reported in Refs [19-21, 56-64]. Prevalence rates for OA and RA based on medical criteria (X-rays and physician examination) $[59,60,63]$ are lower than rates based on interviews. A key reason is different scope: interview rates are person-based (arthritis in any site), whereas medical ones are usually site-specific (hand, knee, hip, etc.). One report that compares interview and exam rates for specific sites finds higher overall rates for the interviews [65]. 
Table 2. Disability and sociomedical characteristics of arthritis and non-arthritis people (percent)

\begin{tabular}{|c|c|c|}
\hline & Arthritis & Non-arthritis \\
\hline $\begin{array}{l}\text { Weighted } n \\
\text { Disability }\end{array}$ & 7057 & 9190 \\
\hline Any difficulty walking & $22.4 \%$ & $8.3 \%$ \\
\hline Any functional limitation & 68.3 & 33.4 \\
\hline $5+$ functional limitations & 27.5 & 9.3 \\
\hline Any ADL difficulty & 17.3 & 6.5 \\
\hline Any IADL difficulty & 14.7 & 7.3 \\
\hline \multicolumn{3}{|l|}{ Sociodemographic } \\
\hline \multicolumn{3}{|l|}{ Age } \\
\hline $55-64$ & $39.0 \%$ & $50.6 \%$ \\
\hline $65-74$ & 36.7 & 31.2 \\
\hline $75-84$ & 19.9 & 14.7 \\
\hline $85+$ & 4.4 & 3.5 \\
\hline \multicolumn{3}{|l|}{ Gender } \\
\hline Male & 34.6 & 50.4 \\
\hline Female & 65.4 & 49.6 \\
\hline \multicolumn{3}{|l|}{ Race } \\
\hline White & 89.0 & 91.0 \\
\hline Non-white & 11.0 & 9.0 \\
\hline \multicolumn{3}{|l|}{ Marital status } \\
\hline Married & 60.4 & 68.9 \\
\hline Widowed & 29.0 & 20.1 \\
\hline Divorced/separated & 6.7 & 6.2 \\
\hline Never married & 3.9 & 4.8 \\
\hline \multicolumn{3}{|l|}{ Education } \\
\hline$<9$ years & 31.6 & 23.7 \\
\hline $9-11$ years & 17.3 & 16.1 \\
\hline High school diploma & 32.8 & 35.6 \\
\hline Any college & 18.3 & 24.6 \\
\hline \multicolumn{3}{|l|}{ Comorbidity } \\
\hline \multicolumn{3}{|l|}{ No. (other) chronic diseases* } \\
\hline 0 & 19.6 & 35.8 \\
\hline 1 & 26.2 & 30.2 \\
\hline 2 & 21.5 & 16.8 \\
\hline $3+$ & 32.7 & 17.2 \\
\hline \multicolumn{3}{|c|}{ No. structural/sensory impairments } \\
\hline 0 & 52.8 & 65.5 \\
\hline 1 & 33.4 & 26.2 \\
\hline $2+$ & 13.8 & 8.3 \\
\hline \multicolumn{3}{|l|}{ BMI† } \\
\hline Underweight $(<20)$ & 8.4 & 8.5 \\
\hline Normal $(20-24.9)$ & 38.4 & 44.4 \\
\hline Overweight $(25-29.9)$ & 35.8 & 35.8 \\
\hline Severe overweight $(\geqslant 30)$ & 17.4 & 11.3 \\
\hline \multicolumn{3}{|l|}{ Target morbidity } \\
\hline \multicolumn{3}{|l|}{ Duration of arthritis } \\
\hline$<1 \mathrm{yr}$ & 6.8 & - \\
\hline $1-5 \mathrm{yr}$ & 27.0 & \\
\hline More than $5 \mathrm{yr}$ & 66.2 & \\
\hline \multicolumn{3}{|l|}{$\begin{array}{l}\text { Most recent medical care } \\
\text { for arthritis }\end{array}$} \\
\hline$<1 \mathrm{yr}$ & 55.4 & - \\
\hline $1+$ yr ago & 25.6 & \\
\hline Never & 19.0 & \\
\hline \multicolumn{3}{|l|}{ Injury origin } \\
\hline No & 94.4 & - \\
\hline Yes & 5.6 & \\
\hline
\end{tabular}

Source: 1984 Supplement on Aging.

* Number of chronic diseases besides arthritis.

$†$ Weight $/$ height ${ }^{2}$. Weight $(\mathrm{kg})$, height $(\mathrm{m})$. The cutpoints for

Under, Normal, etc. are conventional in research.

\section{Disability differentials}

Arthritis people are more likely to be disabled, by two to threefold, than non-arthritis people (Table 2) [see also 66]. Twenty-two percent $(22 \%)$ of people with arthritis have difficulty walking, compared to just $8 \%$ of those without the disease. Functional limitation is common for arthritis people (68\%) and less so for non-arthritis people (33\%); the gap (ratio) is wider for high levels of functional limitation (28 vs $9 \%$ ). Percentages with ADL difficulty are 17 and $6 \%$, respectively; and with IADL difficulty, 15 and $7 \%$.

\section{Social and morbidity differentials}

Table 2 shows social and morbidity characteristics of the two groups. (1) People with arthritis tend to be older, more likely female, more likely widowed and less often married, and less educated. Race distributions are similar for the two groups. These sociodemographic differences are routinely found in other studies as well $[67,68]$. (2) Arthritis people tend to have more chronic conditions (besides their arthritis) and more impairments, and more of them are severely overweight, compared to non-arthritis people. Some of these differentials may be influenced by the older average age of arthritis people. (3) Among just arthritis people, the majority have had arthritis $5+$ years and medical care for it in the past year, and only a small percent attribute their arthritis to a prior injury.

\section{Risk factors for disability}

Logistic regressions with categorical predictors were estimated separately for the arthritis and non-arthritis groups: $Y=f$ [sociodemographic, comorbidity]. Additional regressions including target morbidity were estimated for the arthritis group. Odds ratios (OR) for the predictors are presented in Table 3. We summarize here consistent predictor effects found across the dependent variables. The term "consistent" means that all or almost all ORs show the pattern stated and are statistically significant. Unless stated otherwise, the effects appear for both groups.

Odds of disability rise with age, especially at advanced ages $(85+)$ ( 26 of 30 OR $>1.00,20$ $p \leqslant 0.05,17 p \leqslant 0.01$ ). This age effect is net of other personal and health characteristics, and it suggests to us increasing physiological frailty with age. Women are more likely than men to be disabled (all $10 \mathrm{OR}>1.00,6 p \leqslant 0.05,5$ $p \leqslant 0.01$ ). The significant differences are in two domains: functional limitations and household care. For the former: looking at the 10 specific motion/strength items included in functional 


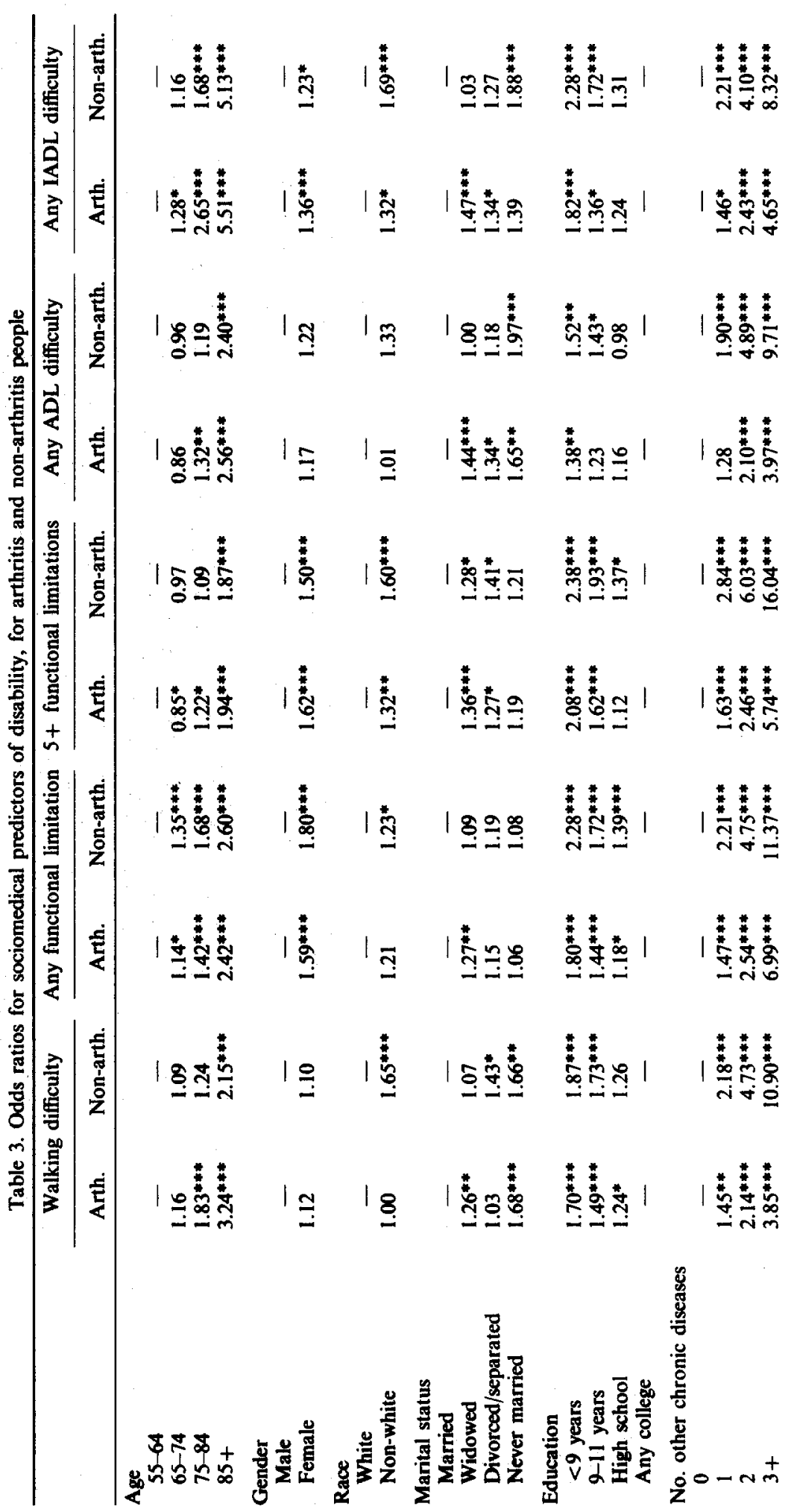


|

|

I

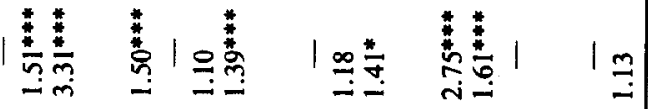

|

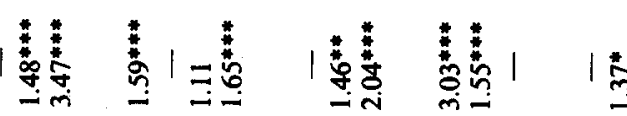

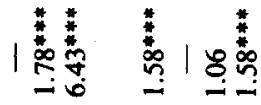

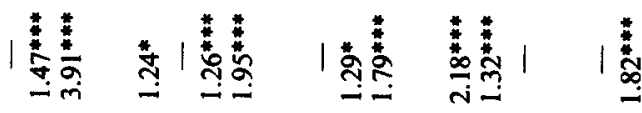

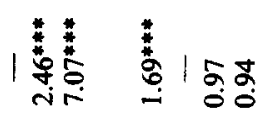

| 等意

8ิ

VI:

*.28

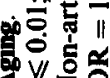

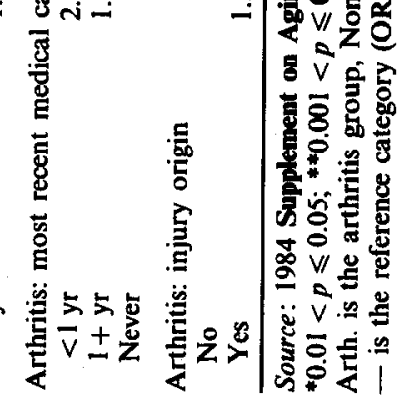


limitations, we find especially large sex differences in strength. This is a longstanding difference in life for women and men and an important component of the SOA result. For the latter: the female excess in IADL disability has no ready interpretation; it may reflect more severe and extensive arthropathy found among women $[25,69]$. Non-white race is associated with disability ( 9 of $10 \mathrm{OR}>1.00,6 p \leqslant 0.05$, $4 p \leqslant 0.01$ ). We have found this race difference repeatedly in our various analyses of the SOA data set; are there possibly lifelong differences in nutritional, physical, or cultural opportunities to explain the disability disadvantage for nonwhites currently in mid and late life?

Married people have lowest likelihood of being disabled (for non-married groups, 29 OR $>1.00,16 p \leqslant 0.05,10 p \leqslant 0.01)$. There is one very consistent finding for the non-married groups: widowed people (with arthritis) suffer disability more often than their married peers. The reasons are not obvious: although disability can be exacerbated when a spouse who helped with household tasks and offered emotional support dies, that is not pertinent here. Our dependent variables measure the intrinsic presence of disability, regardless of whether personal assistance or special aids are present. As education rises, chances of disability decline ( 29 of $30 \mathrm{OR}>1.00,23 p \leqslant 0.05,18 p \leqslant 0.01$ ). This may reflect lesser severity of chronic conditions including arthritis, higher overall robustness, or easier (less physically demanding) household and neighbourhood environments with higher education.

Odds of disability rise steeply with numbers of chronic diseases and impairments people have (all OR $>1.00,27$ of $30 p \leqslant 0.001$ for chronic diseases, all $20 p \leqslant 0.001$ for impairments). Weight status has different effects in the two groups: for arthritis people, severe overweight $(\mathrm{BMI} \geqslant 30)$ and underweight $(\mathrm{BMI}<20)$ are both associated with disability (all 10 OR $>1.00,8 p \leqslant 0.001$ ). There is some evidence of a dose-response relationship; ORs rise from overweight to severe overweight for all 5 dependent variables. But for non-arthritis people, only underweight is associated with disability (all 5 OR $>1.00$, all $p \leqslant 0.001$ ). For them, severe overweight shows 4 of 5 OR $<1.00$, all non-significant.

Among arthritis people, disability rises with disease duration (all $10 \mathrm{OR}>1.00,6 p \leqslant 0.05$, $3 p \leqslant 0.01$ ) and recency of medical care for arthritis (all 10 OR $>1.00,9 p \leqslant 0.001$ ). These findings align with our assumption that longer duration and recent care signal more-severe disease. Injury origin increases slightly the likelihood of physical disability $(p \leqslant 0.05$ for the two functional limitation items, $p=0.06$ for walking), but not social disability.

\section{Summing up:}

(1) Our hypotheses about risks for disability are supported, with the addition of finding underweight an ostensible risk (more discussion shortly).

(2) A given risk factor typically operates on both physical and social disability. (Exceptions are gender and injury origin or arthritis; their effects are largely or solely on physical disability.)

(3) The risk factors for disability are similar for arthritis and non-arthritis people. There are few exceptions; the most important involves weight status. We now explore this exception closely.

\section{The risks of overweight and underweight}

Severe overweight has marked disability impact for arthritis people, but not their nonarthritis peers. This is portrayed in Fig. 1, which shows expected means by weight status for the two groups. The severe overweight ORs are significantly different for arthritis vs nonarthritis people for walking difficulty, high functional limitations, ADL difficulty, and IADL difficulty (4 of 5 dependent variables, 3 $p \leqslant 0.01)$. ( $95 \%$ confidence intervals for severe overweight do not overlap for the arthritis and non-arthritis groups, for the 4 outcomes just noted.)

The consistent positive effect of underweight on disability is surprising. The most likely explanation is that some underweight people are especially ill and have lost weight as a result; thus, our controls for comorbidity could be incomplete in the model. To explore this, we estimated models of the form $Y=f$ [age, gender, race, BMI] within specific levels of comorbidity. We did this with 3 different morbidity indicators: No. chronic diseases besides arthritis $(0,1,2,3-4,5+)$, No. impairments $(0,1,2+)$, and total No. chronic conditions $(0,1,2,3-4,5+)$. All models were estimated for the total sample, the arthritis group, and the non-arthritis group.

Results show that underweight has negligible association with disability among healthy people, but increasing impact as health worsens. Severe overweight, too, has more pronounced 

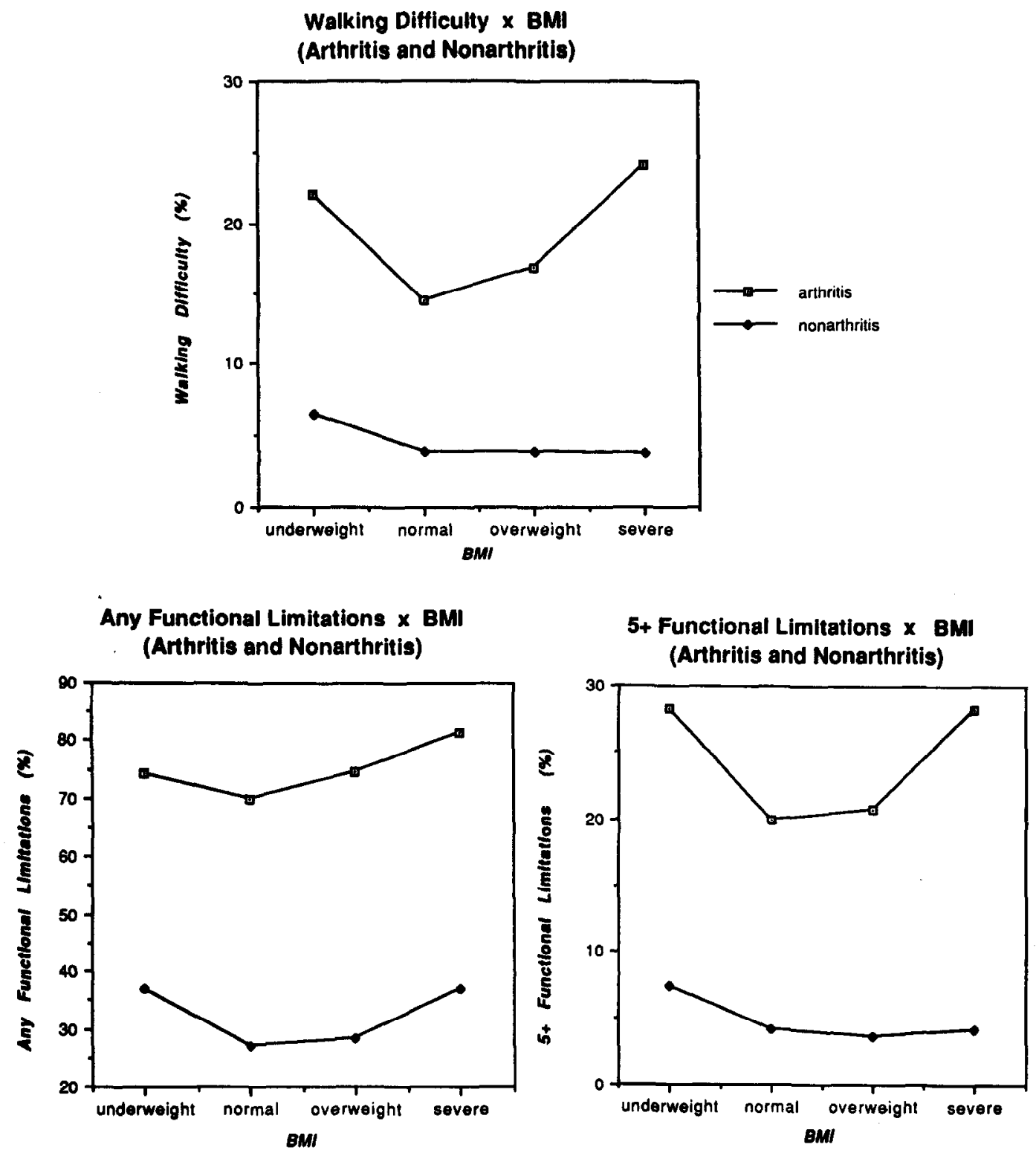

Any ADL Difficulty $x$ BMI (Arthritis and Nonarthritis)

Any IADL Difficulty $\times$ BMI (Arthritis and Nonarthritis)
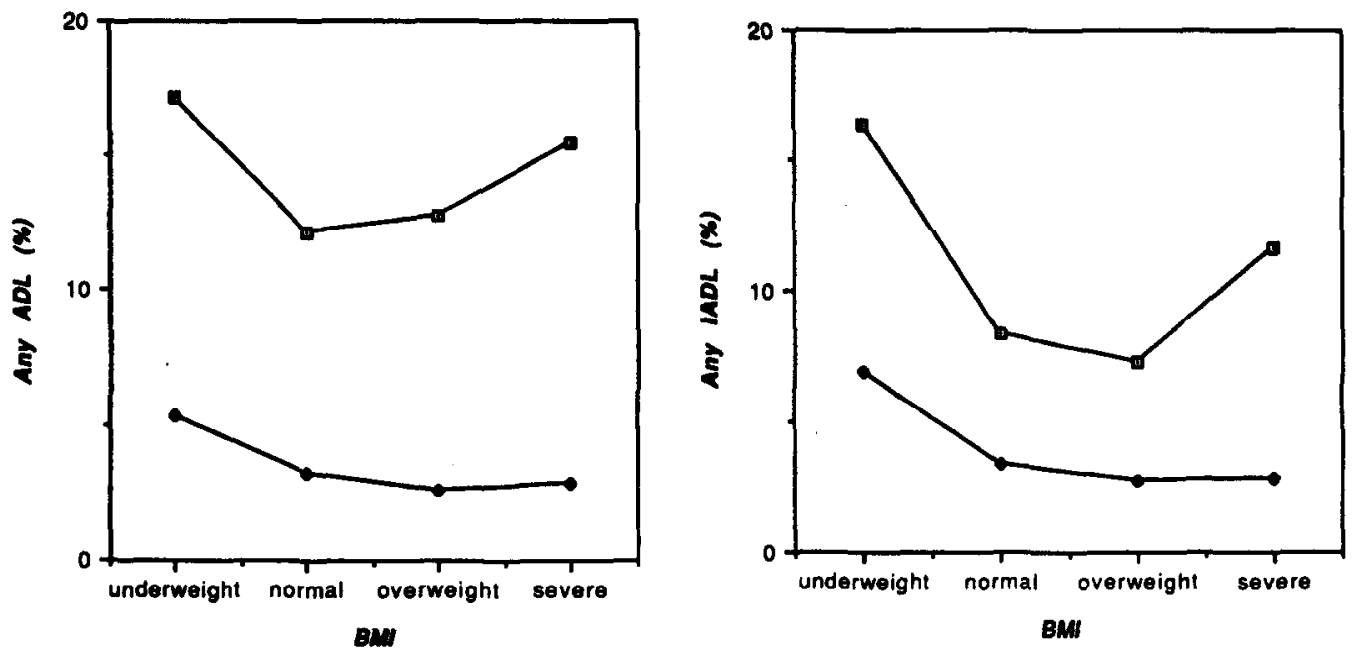

Fig. 1. Body mass index (BMI) and disability, for arthritis and non-arthritis people. Expected percents based on $Y=f$ [sociodemographic, comorbidity]. BMI is one of the comorbidity predictors. 
Walking Difficulty $\times$ BMI
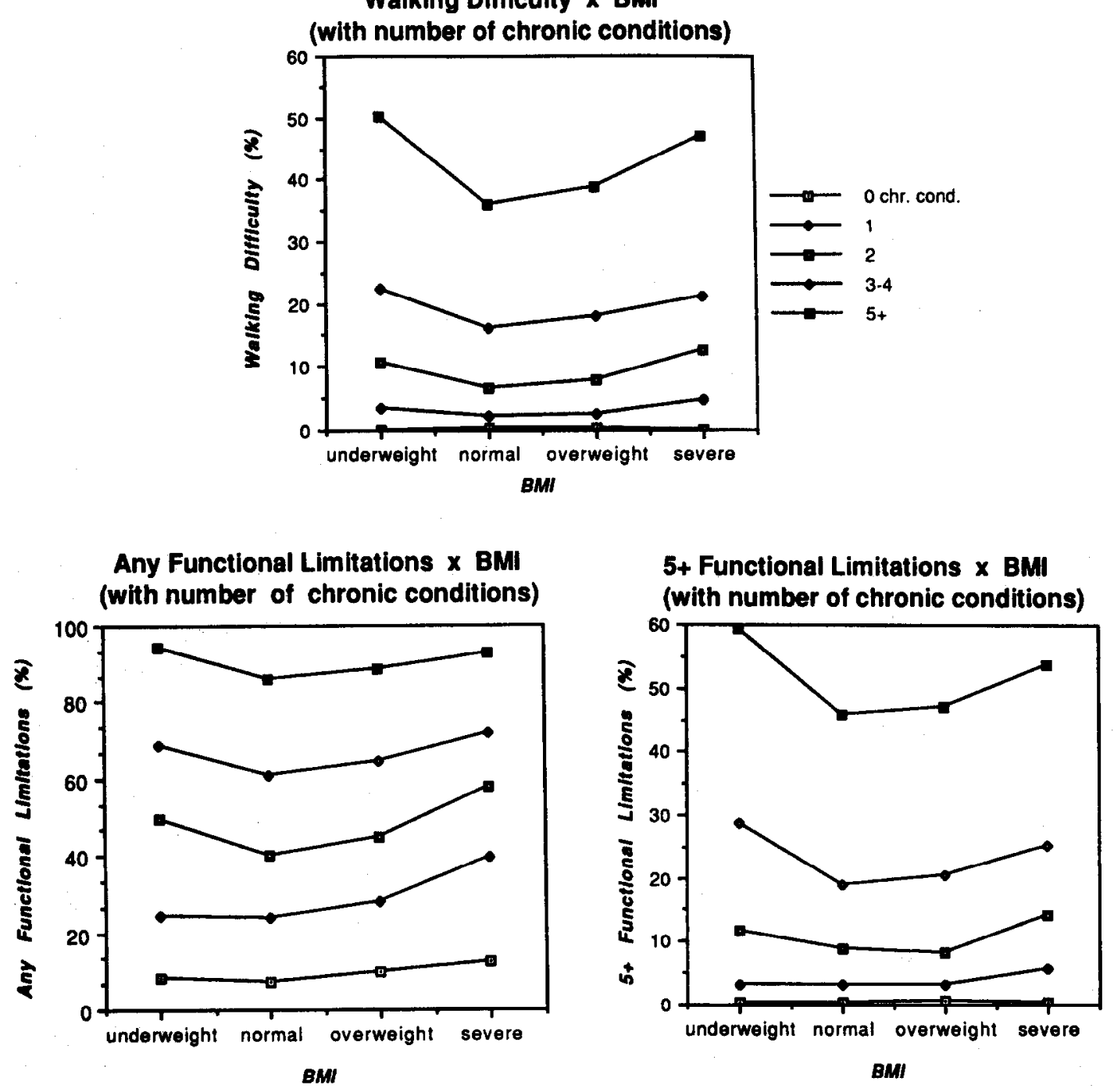

Any ADL Difficulty $x$ BMI (with number of chronic conditions)

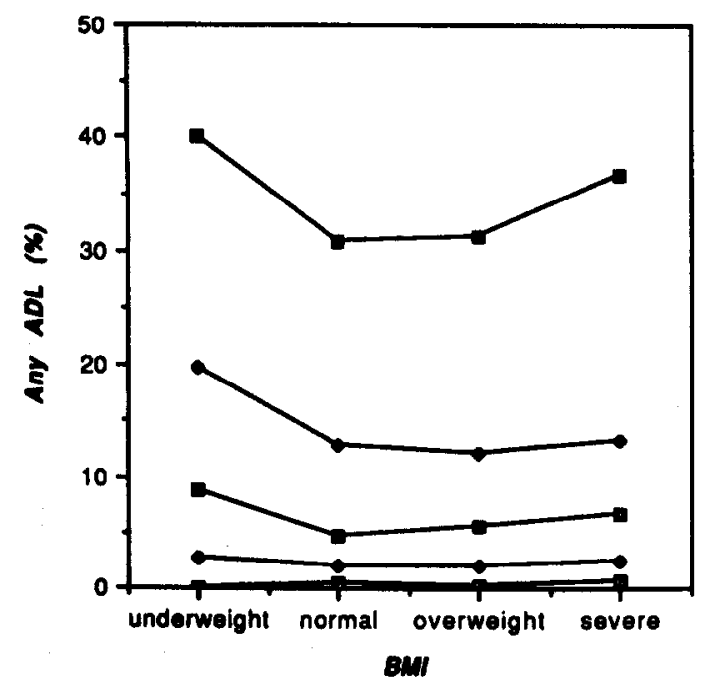

Any IADL Difficulty $\times$ BMI (with number of chronic conditions)

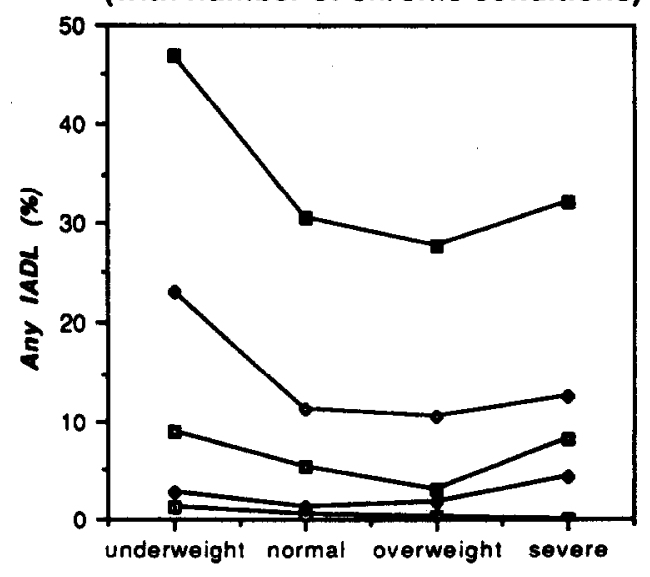

BMI

Fig. 2. BMI and disability, within health strata (total No. of chronic conditions). Expected percents based on $Y=f$ [age, gender, race, BMI]. Age, gender, and race are several of the sociodemographic predictors (see Table 2). Total No. of chronic conditions is a count of all chronic diseases and impairments for the person. 
effects as health worsens; this is especially clear for the arthritis group. Importantly, these patterns are more striking for the two covariates involving diseases than for the impairment covariate. Weight loss is a more typical consequence of multiple diseases than of multiple impairments. To portray these results, Fig. 2 shows the BMI patterns for the total sample stratified by total number of chronic conditions (other results available on request).

In summary, people with numerous chronic conditions are more ill than simple counts of their problems convey [further analyses in Ref. 70]. Very ill people tend to lose weight; the impact of this unmeasured morbidity is carried by underweight in the data set.

\section{Predictive power}

In logistic regression, predictive power is measured by percent reduction in error for a model. It increases as models are enlarged with specific predictors $(X \mathrm{~s})$. Table 4 shows the predictive power for the main model $Y=f$ [sociodemographic, comorbidity] and other larger and smaller models estimated.

The key results: (1) The main model accounts for disability among non-arthritis people better than arthritis people. This result is consistent but has no ready explanation (suggestions welcome). (2) Smaller regressions with each predictor set show that comorbidity is the most important factor for disability, with sociodemographic variables next, and target morbidity last. Thus, a person's collection of chronic con- ditions is the main reason for disability among both arthritis and non-arthritis people. Still, sociodemographic characteristics contain aspects of global robustness, mental wellbeing, culture, and resources that have important main effects. The low importance of target morbidity stems, we believe, from the weak indicators available in the SOA. If more were known about the site(s), symptoms, and severity of arthritis, the contribution of target morbidity would rise and might even displace sociodemographic factors in importance.

\section{Risk factors for subgroups: $O A, R A, A A$}

Although the arthropathies have diverse etiologies and manifestations, personal and medical factors that prompt disability for diseased persons may be shared across them. In other words, risk factors for the diseases may be quite different, but risk factors for disability quite similar.

We study three subgroups of arthritis: OA, RA, and AA (ICD codes noted earlier). There are important differences in disability and sociomedical risks among them: (1) persons with RA are more likely to experience physical and social disability than persons with OA and AA. The AA group has intermediate levels, and OA group lowest levels. (2) RA persons tend to be younger, more female, and more educated than the other groups. Their medical profile is also distinctive; they have fewer impairments (but similar numbers of chronic diseases), and their arthritis has notably longer duration and more

\begin{tabular}{|c|c|c|c|c|c|}
\hline & Walk & Func. lim. & $5+\lim$ & ADL & IADL \\
\hline $\begin{array}{l}\text { Arthritis group } \\
\% \text { reduction error for model: } \\
\text { [Soc, Com] } \\
\text { [Soc, Com, Targ] }{ }^{*}\end{array}$ & $\begin{array}{l}12.3 \\
13.9\end{array}$ & $\begin{array}{l}13.1 \\
14.9\end{array}$ & $\begin{array}{l}14.2 \\
16.6\end{array}$ & $\begin{array}{l}11.4 \\
13.0\end{array}$ & $\begin{array}{l}19.1 \\
20.5\end{array}$ \\
\hline $\begin{array}{l}\text { \% reduction error for smaller models: } \\
\text { [Soc] } \\
\text { [Com] } \\
\text { [Targ] } \\
\text { [Com, Targ] }\end{array}$ & $\begin{array}{r}4.3 \\
10.0 \\
3.0 \\
11.6\end{array}$ & $\begin{array}{r}3.6 \\
11.0 \\
3.5 \\
13.0\end{array}$ & $\begin{array}{r}4.9 \\
11.1 \\
4.3 \\
13.8\end{array}$ & $\begin{array}{r}3.9 \\
9.4 \\
3.1 \\
11.1\end{array}$ & $\begin{array}{r}8.8 \\
13.7 \\
3.1 \\
15.3\end{array}$ \\
\hline $\begin{array}{l}\text { Net contribution of target morbidity } \\
=[\mathrm{Com}, \text { Targ }]-[\mathrm{Com}]\end{array}$ & 1.6 & 2.0 & 2.7 & 1.7 & 1.6 \\
\hline $\begin{array}{l}\text { Non-arthritis group } \\
\% \text { reduction error for model: } \\
\text { [Soc, Com] }\end{array}$ & 22.0 & 18.6 & 24.8 & 21.7 & 24.8 \\
\hline $\begin{array}{l}\% \text { reduction error for smaller models: } \\
\text { [Soc] } \\
{[\text { Com] }}\end{array}$ & $\begin{array}{r}4.7 \\
20.2\end{array}$ & $\begin{array}{r}4.6 \\
15.7\end{array}$ & $\begin{array}{r}5.6 \\
22.2\end{array}$ & $\begin{array}{r}4.7 \\
20.1\end{array}$ & $\begin{array}{r}8.7 \\
20.7\end{array}$ \\
\hline
\end{tabular}

Source: 1984 Supplement on Aging.

Soc = sociodemographic; Com = comorbidity; Targ = target morbidity.

*Estimated for arthritis group only. 
recent medical care than the other groups. (3) AA persons have especially high chronic morbidity (diseases and impairments), relatively long duration of their condition, more recent medical care for it, and especially frequent reports that injury caused the arthritis condition. They are not distinctive in sociodemographic features. (4) OA persons are average in all respects; i.e. like the arthritis sample overall. (5) The three groups do not differ in their weight distributions (BMI).

Logistic regressions (5 dependent variables; $Y=f$ [sociodemographic, comorbidity, target morbidity]) were estimated for each subgroup. The patterns of odds-thus, the identified risks - are essentially the same for OA, RA, and AA as for arthritis overall. Because of small sample sizes, the RA and AA results do not often achieve statistical significance. Not surprisingly, the OA odds are almost identical numerically to those for arthritis overall.

(Only three distinctive results appear in this series of regressions: (1) women with RA are much more likely to have physical dysfunctions than men with RA. This result stands out from the usual situation of small non-significant gender differences, with women's odds above 1.00 . (2) Having other chronic diseases increases disability markedly for AA persons, more so than for OA and RA persons. (3) Severe overweight increases disability for OA and RA, but not for AA persons. We note the three results without interpretation. These distinctive results are minor in the context of fundamental similarity in risk factors for disability for the three subgroups.)

Table 5 presents disability levels of the three subgroups and ORs for the walking variable (others available on request).

\section{DISCUSSION}

A principal concern of epidemiologic research is disease etiology; i.e. identifying factors that initiate pathogenesis and clinical expression of disease. Cross-sectional and longitudinal studies have identified putative and confirmed causal factors for prominent life-threatening diseases, and this knowledge has penetrated medical care and personal lifestyles. Research interest in common non-fatal chronic conditions such as osteoarthritis, low back pain, sensory impairments, urinary incontinence (etc.), had lagged behind. Lacking knowledge about causes, little can be said or done to prevent onset of such conditions.
Most non-fatal chronic conditions are strongly age-related [71], their prevalence rising with advancing age. Thus, as the total population continues to age due to secular fertility declines and to recent mortality declines concentrated at older ages, the aggregate burden of non-fatal diseases and impairments will ascend steadily. In light of this, policy and popular concerns have shifted from simply life's length to its quality for middle-aged and older persons.

Longer life spent with medically managed fatal conditions and accumulating non-fatal ones implies more years of disability for individuals [72-79]. In scientific research, standard epidemiologic perspectives used in analyses of disease onset are now being applied to analyses of disease consequences such as disability. This is called the "epidemiology of disability". The goal is to identify risk factors that propel disability among persons with a given disease. In short, the outcome of interest is $p$ \{disability\} for the general population or persons with a given disease, rather than $p$ \{disease\}.

This analysis is a study of the epidemiology of disability for persons with arthritis. To determine if disability risks are in any way special for arthritis people, we compare them to nonarthritis people throughout the analysis. We find that the same social and medical factors drive disability for arthritis and non-arthritis people, with one important exception.

The similarities are: (1) the primary importance of comorbidity (other chronic diseases and impairments present) and (2) the secondary importance of sociodemographic factors, notably older age, female gender (for functional limitations), non-white race, widowhood (arthritis group only), and low education. (3) For both the arthritis and non-arthritis groups, being underweight is associated with disability. This effect is concentrated among very ill people. Further analyses support the conclusion that underweight itself does not increase disability, but instead that underweight and disability are concurrent outcomes of extreme illness. (Finer controls for extreme illness, if available, should eliminate the underweight effect.)

The important exception is for severe overweight: being very overweight increases disability only among arthritis people. These results align closely with knowledge about OA etiology, showing overweight/obesity to be a strong risk factor for disease onset (referenced earlier). Thus, this modifiable risk is implicated not only 
Table 5. Disability for persons with OA, RA, and AA, and ORs for predictors of walking difficulty†

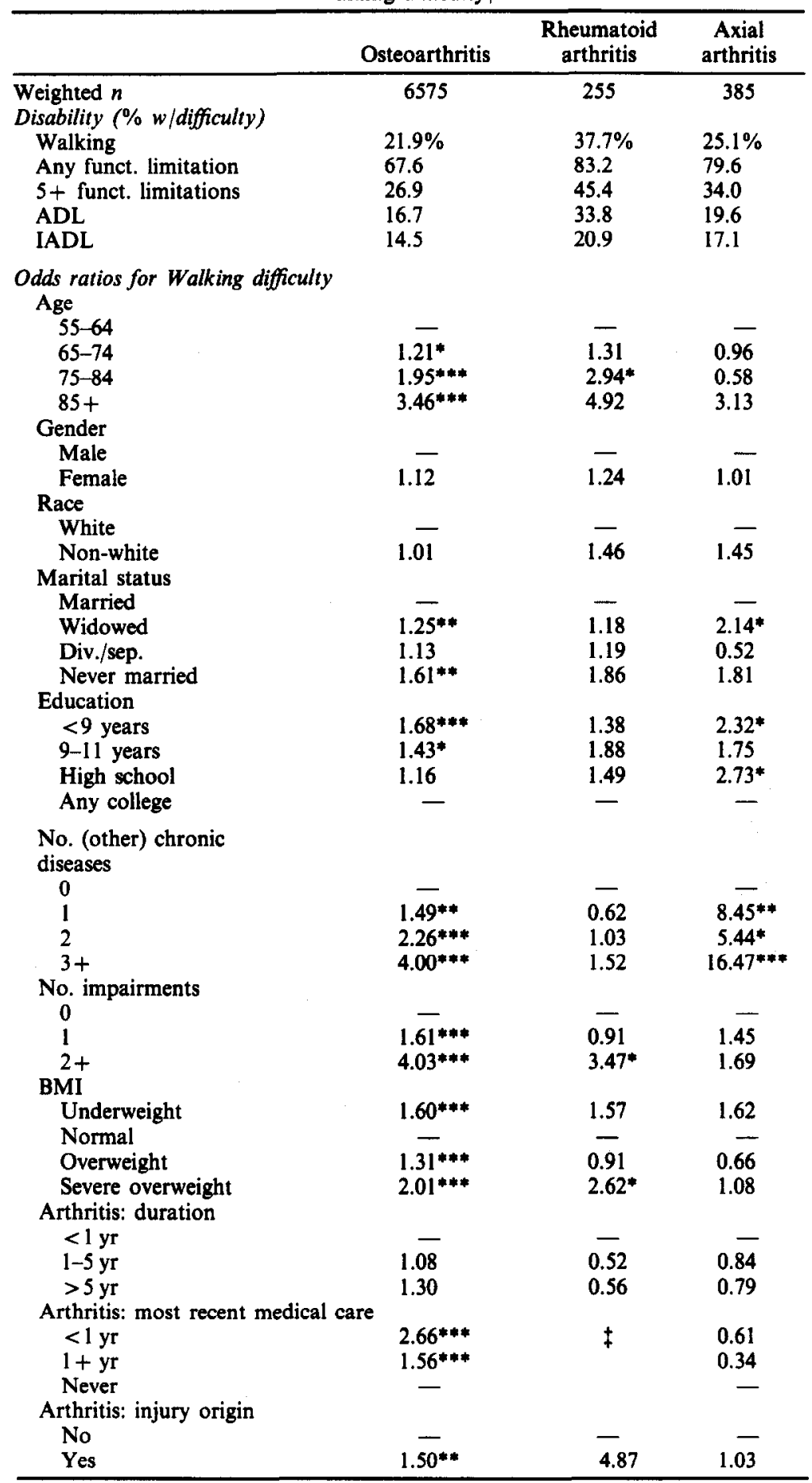

Source: 1984 Supplement on Aging.

${ }^{*} 0.01<p \leqslant 0.05 ;{ }^{* *} 0.001<p \leqslant 0.01 ;{ }^{* * *} p \leqslant 0.001$.

- is the reference category $(O R=1.00)$ for the predictor.

†Osteoarthritis (OA) is ICD 715, 716.9. Rheumatoid arthritis (RA) is 714.0,9. Axial arthritis (AA) is 721 .

¥Not estimated due to perfect association between a category and the dependent variable. 
in arthritis etiology but continues to be important in its functional consequences. The SOA data are cross-sectional and cannot answer with certainty questions of causation-if severe overweight causes or elevates disability for arthritis people, if losing weight alleviates it, or if disability and ensuing reduced activity cause weight gain. We have emphasized the first causal route in our discussion because it parallels the etiologic evidence. But the other routes are plausible and if true, are imbedded in the SOA results as well.

The scope of the SOA analyses deserves mention once again: we identify risk factors for broadly defined areas of physical and social function (walking is the only specific activity studied) among U.S. adults with all forms of arthritis. Data sets with more detail about arthritis sites and symptoms and with diagnosisbased disease status are better suited to locating risk factors for specific activities. We hope this article encourages further study of the disability consequences of overweight in arthritis populations.

Acknowledgements - This research was supported by a Research Grant (R01 AG06616) from the National Institute on Aging. The authors thank James M. Lepkowski (Institute for Social Research and Department of Biostatistics, The University of Michigan) and J. Richard Landis (Hershey Medical Center, Hershey, Penn.) for biostatistical assistance. Two reviewers are thanked for insightful critiques.

\section{REFERENCES}

1. Verbrugge LM. From sneezes to adieux: Stages of health for American men and women. In: Ward RA, Tobin SS, Eds. Health in Aging: Sociological Issues and Policy Directions. New York: Springer, 1987; 17-57.

2. Verbrugge LM, Ascione FJ. Exploring the iceberg: Common symptoms and how people care for them. Med Care 1987; 25: 539-569.

3. Abruzzo JL. Rheumatoid arthritis and mortality. Arthritis Rheum 1982; 25: 1020-1023.

4. Pincus T, Callahan LF, Sale WG, Brooks AL, Payne LE, Vaughn WK. Severe functional declines, work disability, and increased mortality in seventy-five rheumotoid arthritis patients studied over nine years. Arthritis Rheum 1984; 27: 864-872.

5. Anderson JJ, Felson DT. Factors associated with osteoarthritis of the knee in the First National Health and Nutrition Examination Survey (HANES I). Am J Epidemiol 1988; 128: 179-189.

6. Davis MA, Ettinger WH, Neuhaus JM, Hauck WW. Sex differences in osteoarthritis of the knee: The role of obesity. Am J Epidemiol 1988; 127: 1019-1030.

7. Felson DT, Anderson JJ, Naimark A, Walker AM, Meenan RF. Obesity and knee osteoarthritis. Ann Intern Med 1988; 109: 18-24

8. Hartz AJ, Fischer ME, Bril G, Kelber S, Rupley D Jr, Oken $B$ et al. The association of obesity with joint pain and osteoarthritis in the HANES data. J Chron Dis 1986; 39: 311-319.
9. Leach RE, Baumgard S, Broom J. Obesity: Its relationship to osteoarthritis of the knee. Clin Orthopaedics 1973; 93: 271-273.

10. Carman WJ. Factors associated with pain and osteoarthritis in the Tecumseh Community Health Study. Paper presented at the Conference on Pain in Osteoarthritis. Cancun: Mexico, February 1989.

11. Engel A. Osteoarthritis and Body Measurements. Vital and Health Statistics, Series 11, No. 29. Washington, D.C.: National Center for Health Statistics, 1968.

12. Kellgren JH, Lawrence JS. Osteoarthrosis and disk degeneration in an urban population. Ann Rheum Dis 1958; 17: 388-396.

13. Fitti JE, Kovar MG. The Supplement on Aging to the 1984 National Health Interview Survey. Vital and Health Statistics, Series 1, No. 21; DHHS Publ. No. (PHS)87-1323. Hyattsville, Md: National Center for Health Statistics; 1987.

14. Cox BG, Cohen SB. Methodological Issues for Health Care Surveys. New York: Marcel Dekker; 1985.

15. Kish L, Groves RM, Krotki KP. Sampling errors for fertility surveys. World Fertility Survey, Occasional Survey Paper 17. London, 1976.

16. Kish L, Frankel MR. Inference from complex samples. J R Stat Soc 1974; Series B, 36: 1-37.

17. Verma V, Scott C, O'Muircheartaigh C. Sample designs and sampling errors for the World Fertility Survey. J R Stat Soc 1980; Series A, 143: 431-473.

18. Arthritis Foundation, The. In: Schumacher HR Jr, Ed. Primer on the Rheumatic Diseases, 9th edn. Atlanta, $\mathrm{Ga}, 1988$.

19. Felson DT. Epidemiology of hip and knee osteoarthritis. In: Szklo M, Gordis L, Gregg MB, Levine MM, Eds. Epidemiologic Reviews, Vol. 10. Baltimore, Md: The Johns Hopkins University School of Hygiene and Public Health; 1988. 1-28.

20. Kelsey JL. Epidemiology of Musculoskeletal Disorders. New York: Oxford University Press, 1982.

21. Masi AT, Medsger TA $\mathrm{J}_{\mathrm{r}}$. Epidemiology of the rheumatic diseases. In: McCarty DJ, Ed. Arthritis and Allied Conditions: A Textbook of Rheumatology, 11th edn. Philadelphia: Lea \& Febiger, 1988.

22. Kuller LH. The epidemiology of osteoarthritis. In: Lawrence RC, Shulman, LE, Eds. Epidemiology of the Rheumatic Diseases, New York: Gower Medical Publishers Ltd; 1984: 277-281.

23. Mankin HJ, Brandt KD, Shulman LE. Workshop on etiopathogenesis of osteoarthritis. J Rheumatol 1986; 13: $1127-1160$

24. Moskowitz RW, Howell DS, Goldberg VM, Mankin HJ, Eds. Osteoarthritis-Dlagnosis and Management, Philadelphia: W. B. Saunders Co.; 1984.

25. Peyron JG. Epidemiologic and etiologic approach of osteoarthritis. Semin Arthritis Rheum 1979; 8: 288-306.

26. Verbrugge LM. Disability. Rheumatic Dis Clin North Am 1990; 16: 741-761.

27. Ernst M, Ernst NS. Functional capacity. In: Mangen DJ, Peterson WA, Eds. Research Instruments in Social Gerontology, Vol. 3. Minneapolis, Minn.: University of Minnesota Press, 1984: 9-84.

28. Feinstein AR, Josephy BR, Wells CK. Scientific and clinical problems in indexes of functional disability. Ann Intern Med 1986; 105: 413-420.

29. Kane RA, Kane RL. Assessing the Elderly: A Practical Guide to Measurement. Lexington, Mass.: D. C. Heath and Co.; 1981.

30. McDowell I, Newell C. Measuring Health: A Guide to Rating Scales and Questionnaires. New York: Oxford University Press; 1987.

31. Stewart AL, Ware JE Jr, Brook RH, Davies-Avery A. Conceptualization and Measurement of Health for Adults in the Health Insurance Study, Vol. II: Physical 
Health in Terms of Functioning. Report No. R-1987/2-HEW. Santa Monica, Calif:: The Rand Corporation; 1978.

32. Harrison GG. Height-weight tables. Ann Intern Med 1985; 103: 989-994.

33. Metropolitan Life Foundation. 1983 Metropolian Height and Weight Tables. Stat Bull 1983; 64: 2-9.

34. Seltzer F. Measurement of overweight. Stat Bull 1984; 65: 20-23.

35. Simopoulous AP, VanItallie TB. Body weight, height, and longevity. Ann Intern Med 1984; 100: 285-295.

36. Stavig GR, Leonard AR, Ingra A, Felten P. Indices of relative body weight and ideal weight charts. J Chron Dis 1984; 37: 255-262.

37. Nathanson CA, Lorenz G. Women and health: The social dimensions of biomedical data. In: Giele JZ, Ed. Women in the Middle Years. New York: Wiley; 1982: 37-87.

38. Verbrugge LM. Gender and health: An update on hypotheses and evidence. J Health Soc Behav 1985; 26: 156-182.

39. Verbrugge LM, Wingard DL. Sex differentials in health and mortality. Women and Health 1987; 12: 103-145.

40. Chandra V, Szklo M, Goldberg R, Tonascia J. The impact of marital status on survival after an acute myocardial infarction: A population-based study. Am J Epidemiol 1983; 117: 320-325.

41. Kaprio J, Koskenvua M, Rita H. Mortality after bereavement: A prospective study of 95,647 widowed persons. Am J Public Health 1987; 77: 283-287.

42. Verbrugge LM. Marital status and health. J Marriage Fam 1979; 41: 267-285.

43. Antonovsky A. Social class, life expectancy, and overall mortality. In: Jaco EG, Ed. Patients, Physicians, and Ilness. New York: Free Press; 1972: 5-30.

44. Dutton DB. Social class, health, and illness. In: Aiken LH, Mechanic D, Eds. Applications of Social Science to Clinical Medicine and Health Policy. New Brunswick, N.J.: Rutgers University Press; 1986: 31-62.

45. Kitagawa EM, Hauser PM. Differential Mortality in the United States. Cambridge, Mass.: Harvard University Press; 1973.

46. Pincus T, Callahan LF, Burkhauser RV. Most chronic diseases are reported more frequently by individuals with fewer than 12 years of formal education in the age 18-64 United States population. J Chron Dis 1987; 40: 865-874.

47. Syme SL, Berkman LF. Social class, susceptibility, and sickness. Am J Epidemiol 1976; 104: 1-8.

48. Andres $\mathbf{R}$. Effect of obesity on total mortality. Int $\mathbf{J}$ Obes 1980; 4: 381-386.

49. Van Itallie TB. Health implications of overweight and obesity in the United States. Ann Intern Med 1985; 103: 983-988.

50. Sidney S, Friedman GD, Siegelaub AB. Thinness and mortality. Am J Public Health 1987; 77: 317-322.

51. Wadden TA, Stunkard AJ. Social and psychological consequences of obesity. Ann Intern Med 1985; 103: 1062-1067.

52. McLean RA, Moon M. Health, obesity, and earnings. Am J Public Health 1980; 70; 1006-1009.

53. Seidell JC, De Groot LCPGM, Van Sonsbeek JLA, Deurenberg P. Hautvast JGAJ. Associations of moderate and severe overweight with self-reported illness and medical care in Dutch adults. Am J Public Health 1986; 76: 264-269.

54. Felson DT, Naimark A, Anderson J, Kazis L, Castelli W, Meenan RF. The prevalence of knee osteoarthritis in the elderly: The Framingham Osteoarthritis Study. Arthritis Rheum 1987; 30: 914-918.
55. Forman MD, Malamet R, Kaplan D. A survey of osteoarthritis of the knee in the elderly. $\mathbf{J}$ Rheunatol 1983; 10: 282-287.

56. Lawrence RC, Hochberg MC, Kelsey JL, McDuffie FC, Medsger TA Jr, Felts WR, Shulman LE. Estimates of the prevalence of selected arthritis and musculoskeletal diseases in the United States. J Rheumatol 1989; 16: 427-441.

57. Carter ET, McKenna CH, Brian DD, Kurland LT. Epidemiology of ankylosing spondylitis in Rochester, Minn. 1935-1973. Arthritis Rheum 1979; 22: 365-370.

58. Cobb S. The Frequency of the Rheumatic Diseases. Cambridge, Mass.: Harvard University Press; 1971.

59. Engel A, Burch TA. Osteoarthritis in Adults by Selected Demographic Characteristics, United States, 1960-1972. Vital and Health Statistics, Series 11, No. 20. Washington, D.C.: National Center for Health Statistics; 1966.

60. Engel A, Roberts J, Burch TA. Rheumatoid Arthritis in Adults, United States, 1960-1962. Vital and Health Statistics, Series 11, No. 17. Washington, D.C.: National Center for Health Statistics; 1966.

61. Lawrence JS. Rheumatism in Populations. London: William Heinemann Medical Books Ltd; 1977.

62. Lawrence RC, Shulman LE, Eds. Epidemiology of the Rheumatic Diseases. New York: Gower Medical Publishers; 1984.

63. Maurer K. Basic Data on Arthritis-Knee, Hip, and Sacroiliac Joints in Adults Ages 25-74 Years, United States, 1971-1975. Vital and Health Statisties, Series 11, No. 213. DHEW Publ. No. (PHS) 79-1661. Hyattsville, Md: National Center for Health Statistics; 1979.

64. Mikkelson WM, Dodge HJ, Duff IF, Kato H. Estimates of the prevalence of rheumatic diseases in the population of Tecumseh, Michigan, 1959-60. J Chron Dis 1967; 20: 351-369.

65. Cunningham LS, Kelsey JL. Epidemiology of musculoskeletal impairments and associated disability. Am J Public Health 1984; 74: 574-579.

66. Verbrugge LM, Lepkowski JM, Konkol LL. Levels of disability among U.S. adults with arthritis. J Gerontol: Soc Sci In press; 1991.

67. Pincus T, Mitchell JM, Burkhauser RV. Substantial work disability and earnings losses in individuals less than age 65 with osteoarthritis: Comparisons with rheumatoid arthritis. J Clin Epidemiol 1989; 42: 449-457.

68. Yelin EH, Henke CJ, Epstein WV. Work disability among persons with musculoskeletal conditions. Arthritis Rheum 1986; 29: 1322-1333.

69. Peyron JG. The epidemiology of osteoarthritis. In: Moskowitz RW, Howell DS, Goldberg VM, Mankin JH, Eds. Osteoarthritis-Diagnosis and Management. Philadelphia, Penn.: W. B. Saunders Co; 1984: 9-27.

70. Verbrugge LM, Lepkowski JM, Imanaka Y. Comorbidity and its impact on disability. Milbank Mem Fund Q/Health Soc 1989; 67: 450-484.

71. Brody JA, Schneider EL. Diseases and disorders of aging: An hypothesis. J Chron Dis 1986; 11: 871-876.

72. Chirikos TN. Accounting for the historical rise in work disability prevalence. Milbank Mem Fund $Q /$ Health Soc 1986; 64: 271-301.

73. Colvez A, Blanchet M. Disability trends in the United States population 1966-76: Analysis of reported causes. Am J Public Health 1981; 71: 464-471.

74. Crimmins EM, Saito $Y$. Changes in life expectancy and disability free life expectancy in the U.S.: 1970-1980. Unpublished manuscript, 1987. (Crimmins: Andrus Gerontology Center, University Park MC-0191, Los Angeles, CA 90089-0191, U.S.A.)

75. Rice DP, LaPlante MP. Chronic illness, disability, and increasing longevity. In: Sullivan S, Lewin ME, Eds. 
Ethics and Economics of Long-Term Care. Washington, D.C.: American Enterprise Institute; 1988: 9-55.

76. Rogers RG, Rogers A, Belanger A. Active life among the elderly in the United States: Multistate life-table estimates and population projections. Milbank Mem Fund Q/Health Soc 1989; 67: 370-411.

77. Verbrugge LM. Longer life but worsening health? Trends in health and mortality of middle-aged and older persons. Milbank Mem Fund Q/Health Soc 1984; 62: 475-519.

78. Verbrugge LM. Recent, present, and future health of American adults. In: Breslow L, Fielding JE, Lave LB, Eds. Annual Review of Public Health, Vol. 10. Palo Alto, Calif.: Annual Reviews Inc; 1989: 333-361.

79. Yelin E. Disabled concern: The social context of the work disability problem. Milbank Mem Fund Q/Health Soc 1989; 67(Suppl. 2, Part 1): 114-165.

80. Health Care Financing Administration. The International Classification of Diseases, 9th edn, Clinical Modification. DHHS Publ. No. (PHS) 80-1260. Washington, D.C.: Government Printing Office; 1980.

81. National Center for Health Statistics. Medical Coding Manual and Short Index, National Health Interview Survey, 1982. Hyattsville, Md: NCHS; 1985.

\section{APPENDIX 1}

\section{ICD-9 Titles and Codes Included in Arthritis}

The ICD-9 codes included in arthritis are 711.b,0,9; $712 . b, 8,9 ; 714-716,720.0 ; 721$. Shown here are the group (3-digit) titles that contain arthritis codes, then the number of SOA records for specific (4-digit) codes (not shown if zero cases).

711 Arthropathy associated with infections (selected titles 711.b, 0, 9)

711.0 Pyogenic arthritis

712 Crystal arthropathies (selected titles $712.6,8,9$ )

712.b Crystal arthropathy, NEC

714 Rheumatoid arthritis and other inflammatory arthropathies

714.0 RA 238

714.9 Unspecified inflammatory polyarthopathy 11

715 Osteoarthrosis and allied disorders

715.0 Generalized osteoarthrosis

715.8 OA with mention of $2+$ sites

$715.9 \mathrm{OA}$, unspecified if generalized or localized

716 Other and unspecified arthropathies

716.1 Traumatic arthropathy

716.2 Allergic arthritis

716.3 "Climacteric arthritis"

716.5 Unspecified polyarthritis

716.6 Unspecified monoarthritis

716.8 Other specified arthropathy

716.9 Arthropathy, unspecified

720 Ankylosing spondylitis and other inflammatory spondylopathies (selected title 720.0)

720.0 Ankylosing spondylitis

721 Spondylosis and allied disorders

721.0 Cervical spondylosis $w / 0$ myelopathy 74

721.3 Lumbosacral spondylosis w/o myelopathy 2

721.8 Other allied disorders of spine Total

721.9 Spondylosis of unspecified site 360

Source: 1984 Supplement on Aging.

NEC means not elsewhere classifiable.

\section{APPENDIX 2}

Question Wordings for the 5 Disability Items

Any difficulty walking

"Because of a health or physical problem, do you have any difficulty walking?".

\section{Any functional limitation; $5+$ functional limitations}

"By yourself and not using aids, do you have any difficulty-walking for a quarter of a mile (that is about 2 or 3 blocks)? Walking up 10 steps without resting? Standing or being on your feet for about 2 hours? Sitting for about 2 hours? Stooping, crouching, or kneeling? Reaching up over your head? Reaching out (as if to shake someone's hand)? Using your fingers to grasp or handle? Lifting or carrying something as heavy as $25 \mathrm{lb}$ (such as two full bags of groceries)? (If YES) Lifting or carrying something as heavy as $10 \mathrm{lb?"}$ (range 0-10).

\section{Any $A D L$ difficulty}

"Because of a health or physical problem, do you have any difficulty-bathing or showering? Dressing? Eating? Getting in and out of bed or chairs? Using the toilet, including getting to the toilet?" ( 1 if YES on any item).

\section{Any IADL difficulty}

"Because of a health or physical problem, do you have any difficulty-preparing your own meals? Shopping for personal items (such as toilet items or medicines)? Managing your money (such as keeping track of expenses or paying bills)? Using the telephone? Doing light housework (like doing dishes, straightening up, or light cleaning)?" (1 if YES on any item). For IADLs, people who answered that they don't do the activity for a reason besides health (cultural or social) are scored 0 , as having no disability; thus we assume they would be capable of doing the activity if they had to.

For readers familiar with the SOA, we note: (1) Walking and getting outside are included in the ADL section of the SOA. But conceptually, they pertain to physical disability, so we treat them as such. (2) Doing heavy housework is included in the IADL section. We use only the light housework item since it is more sensitive to serious health problems. 